\title{
A Simulation Model for Pricing the Spread in a Credit Default Swap: Application and Analysis"
}

\author{
Madhvi Sethi ${ }^{1 *}$, Parthiv Thakkar ${ }^{2}$ and Zahid M. Jamal ${ }^{3}$ \\ ${ }^{1}$ Associate Professor, Symbiosis Institute of Business Management Bengaluru, Symbiosis \\ International University, Pune - 412115, Maharashtra, India \\ ${ }^{2,3}$ Student Research Assistant, Symbiosis Institute of Business Management Bengaluru, Symbiosis \\ International University, Pune - 412115, Maharashtra, India
}

\begin{abstract}
This paper explores pricing the contract of a Credit Default Swap (CDS) using a simulation model. It attempts to determine the spread value which is a periodic payment to be made by the protection buyer. It also helps in identifying the factors that should be taken into account to determine the true value of the payment which would hedge the risk in case of a credit event by the issuer of the underlying asset. The paper uses the Hull and White pricing model for creating the simulation model. This model is then applied to analyse CDSs of countries having different credit ratings. The paper using the model analyses the actual and estimated spread of the different countries and discusses the possible reasons for the same. This model is a simple tool to get an estimate of the price at which contract of CDS can be executed. We have been able to get a spread which is close to the actual spread for different credit rated countries. Our model provides an insight into the practical application of the pricing of CDS by trying to derive the spread in a simplified way. It also brings forth the results of the simulation to show that if credit rating declines, then the value of the spreads increase which means the contract becomes expensive to purchase.
\end{abstract}

Keywords: Credit Default Swap, Simulation, Spreads

\section{Introduction}

A Credit Default Swap (CDS) is a derivative instrument that is designed to transfer the credit exposure particularly for fixed income securities (bonds and loans). The contract usually contains three parties namely,

- Issuer of the debt security (reference entity in a CDS contract)

- Buyer of the debt security (CDS buyer)

- Third party (CDS seller usually big banks)

The CDS offers insurance to the buyer of the debt security. In case of a credit event (default committed by the issuer of the security), the seller of the CDS will indemnify all losses incurred by the buyer i.e., he buys the debt security from the bond buyer. In return, the bond buyer pays a periodical premium to the third party until a credit event occurs. These premiums are usually a fixed percent of the par value of the bond. This helps to reduce the credit risk of the lender of the debt contract. (Wen, Yuan and Kinsella Jacob (2013). "Credit Default Swaps - Pricing Theory, Real data analysis and Classroom application using Bloomberg terminal.” New York.)

To better understand how the cash flows of a CDS contract work, let us look at the following example. Company A is issuing a 10 -year bond with a coupon of $12 \%$ and $\$ 1$ million par value. Company $\mathrm{B}$ has excess funds and decides to invest money on the bonds of

\footnotetext{
*Email: madhvi.sethi@sibm.edu.in \#This is the revised and modified version of the article, presented in the $6^{\text {th }}$ International Conference on Emerging Trends in Finance, Accounting and Banking, SDMIMD, August 2017.
} 
Company A. But the bonds are BBB rated by Standard \& Poor's (S\&P) and he wants to invest in AA rated securities. In this case, they enter into a CDS with Big Republic bank which is AAA rated. In this case, if Company A defaults, Big Republic Bank will indemnify Company B for all his loses. In return, Company B will pay periodical premium, let's say $1 \%$ of the par value of the bond. In this case, the cash flows would be as shown in Figure 1.
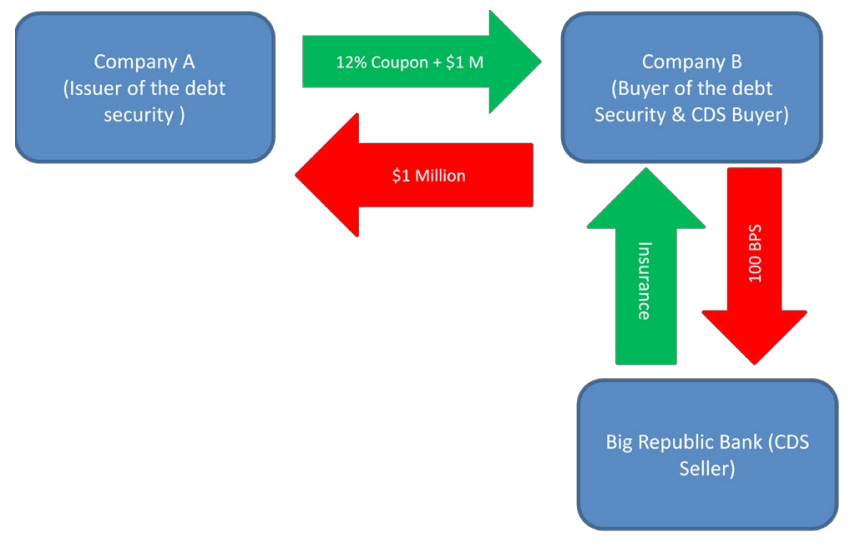

Source: Wen, Yuan (2013). "Credit Default Swaps - Pricing Theory, Real data analysis and Classroom application using Bloomberg terminal." New York.

Figure 1. Cash Flows of a CDS Contract (Plain Vanilla).

The par value of a CDS is notional and in the above case is $\$ 1$ million. The premium is called spread which is usually certain basis point of the par value. As the credit risk increases, the spread also increases because of a high chance of default. When there is a default, the CDS buyer will get a payment from the CDS seller. This payment is referred to as payoff from the CDS which is different from the amount of debt. This is because the recovery rate is non zero in most cases. When bonds default, bondholders get a part of their investment back upon liquidation.

A CDS has value and this value changes with time. Thus, it is necessary to monitor its prices or spreads. These spreads change due to various factors including discount factors, changes in the macro-economic condition, etc.

This paper also interprets the movements of spread and the impacts it has on the value of the underlying instrument. To explicitly explain following are the objectives:

- To create a simple CDS pricing model

- To determine the spread value which is a periodic payment to be made by the protection buyer.

- To identify the factors that should be taken into account to determine the true value of the payment which would hedge the risk in case of a credit event by the issuer of the underlying asset.

In this paper, we have used historical sovereign data based on S\&P to price a CDS. We compared the calculated spreads with the actual spreads. Since there were a lot of fluctuation in the actual spreads among countries within a particular credit rating, we clubbed some countries with similar credit rating and took a simple average to avoid extremities. The first and second section contains the review of the literature followed by the data and the methodology used in the model. The third section contains the actual workings of the pricing model. The fourth section contains the limitation of the model and the last section contains the application of these spreads.

\section{Review of Literature}

Several researchers have explored the area of modelling credit default swaps. The pioneer work by Hull and White (2000) provides the basis of these models. The Hull and White methodology has been adopted in different ways by researchers and practitioners. They tried to provide a value to CDS when there is no counterparty risk. They did the same by calculating the risk neutral probability through the bond yields.

Wen and Kinsella (2013) applied the model by Hull et. al, They described the theory used by bloomberg in calculating the spreads and the factors that it takes into account to value the contract.

Some studies have been done incorporating the risk of default. The study by Duffie (1999) explains the concept of hazard rate which is the probability of happening of the credit event (Poisson distribution). From this risk neutral probability of default the paper tries to estimate the value of par spread of the CDS contract. 
Scholars have been contributing in this area of research by combining different aspects with the basic pricing model of the CDS instruments. In the area of risk management, the paper by Jarrow and Turnbull (1995) talks about hedging the credit risk of the derivativs contract particularly the swaps where the credit risk arises from two situation, one being the credit default of underlying and other being credit default by the protection seller. This paper takes into account a lot of assumptions in terms of economy and the way markets would function.

Jarrow and Yu (2001) extended the defaultable bond pricing formula to include the ineterdependent default risk. This means the probability that a counterparty's deafult might lead to its own default. This research could be used as a parameter for calculating spreads.

The model of Merton (1974) is a structural model and its basic idea is to use option pricing technique to value the default risk spreads of fixed income instruments. The bond which is generally the underlying instrument for the CDS contract has the default risk spreads which can be measure through this model. However this model uses the value of the form as one of the parameter which is very dificult to estimate.
After going through the several studies, following objectives were formulated:

- To create a simple CDS pricing model

- To identify the factors that should be taken into account to determine the intrinsic value of the premiums which would hedge the risk in case of a credit event by the issuer of the underlying asset.

- To apply it for instruments from different countries having different credit ratings.

\section{Data and Methodology}

The study has used data from the Bloomberg terminal extensively.

Real time and historical information was extracted from the Bloomberg terminal. We extracted the country credit rating, actual spreads and discounting factors for our model from Bloomberg. We priced one, three and five year CDS contracts. The pricing model is developed using data taken as on $31^{\text {st }}$ July 2017.

Firstly, to find the country credit rating, the CSDR function can be used on the Bloomberg terminal (Figure 2). We filtered a few countries from B-, BB- and B ratings.

\begin{tabular}{|c|c|c|c|c|c|c|c|c|c|}
\hline \multirow{3}{*}{$\begin{array}{l}\text { Global } \\
\text { o Foreign Currency }\end{array}$} & \multicolumn{4}{|c|}{ 1) Settings } & & & & \multicolumn{2}{|c|}{ Sovereign Ratings } \\
\hline & \multirow{2}{*}{\multicolumn{2}{|c|}{$\begin{array}{c}\text { - Local Currency } \\
\text { Foreign Curr }\end{array}$}} & \multicolumn{2}{|c|}{$\square$ Ignore Watch } & \multicolumn{4}{|c|}{ Highlight changes in last } & 20 business days. \\
\hline & & & Icy Lon & arm & For & $\operatorname{gn} \mathrm{Cu}$ & Sho & $\mathrm{rm}$ & 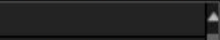 \\
\hline Country & Moody's & S\&P & Fitch & R\&I & Moody's & S\&P & Fitch & R\&I & Last Update \\
\hline & & & & & & & & & MM/DD/YYYY/日 \\
\hline 21) Turkey & $\mathrm{Ba} 1$ & $\mathrm{BBu}$ & $\mathrm{BB}+$ & BB+ & NR & $\mathrm{Bu}$ & B & NR & $08 / 07 / 2017$ \\
\hline 22) DR Congo & B3 & $\operatorname{ccC}+$ & NR & NR & NR & C & NR & NR & $08 / 04 / 2017$ \\
\hline 23) Iraq & Caa1 & B- & B- & NR & NR & B & B & NR & $08 / 03 / 2017$ \\
\hline 24) Republic of Congo & $\mathrm{Caa} 2$ & SD & RD & NR & NR & D & C & NR & $08 / 02 / 2017$ \\
\hline 25) Bahrain & B1u & BB- & $\mathrm{BB}+$ & NR & NR & B & B & NR & $07 / 28 / 2017$ \\
\hline 26) Cyprus & (P)Ba3 & $\mathrm{BB}+$ & BB- & NR & NP & B & B & NR & $07 / 28 / 2017$ \\
\hline 27) Oman & Baa2 & $\mathrm{BB}+$ & BBB & NR & NR & B & F2 & NR & $07 / 28 / 2017$ \\
\hline 28) Andorra & NR & BBB & BBB & NR & NR & $A-2$ & F3 & NR & $07 / 28 / 2017$ \\
\hline 29) Dominican Republic & $\mathrm{Ba} 3$ & BB- & BB- & NR & NR & B & B & NR & $07 / 20 / 2017$ \\
\hline 30) Denmark & Aaa & AAA & AAA & AAA & NR & $A-1+$ & $\mathrm{F} 1+$ & NR & $07 / 19 / 2017$ \\
\hline 31) Honduras & B2 & BB- & NR & NR & NR & B & NR & NR & $07 / 18 / 2017$ \\
\hline 32) Chile & $\mathrm{Aa} 3$ & A+ & A+ & NR & NR & $A-1$ & F1+ & NR & $07 / 13 / 2017$ \\
\hline 33) Venezuela & Caa3 & CCC- & $\mathrm{CCC}$ & NR & NR & C & C & NR & $07 / 11 / 2017$. \\
\hline
\end{tabular}

Figure 2. Source: Bloomberg. 
To understand the amount of amount of debt already taken by these countries, the WCDM function was used (Figure 3).

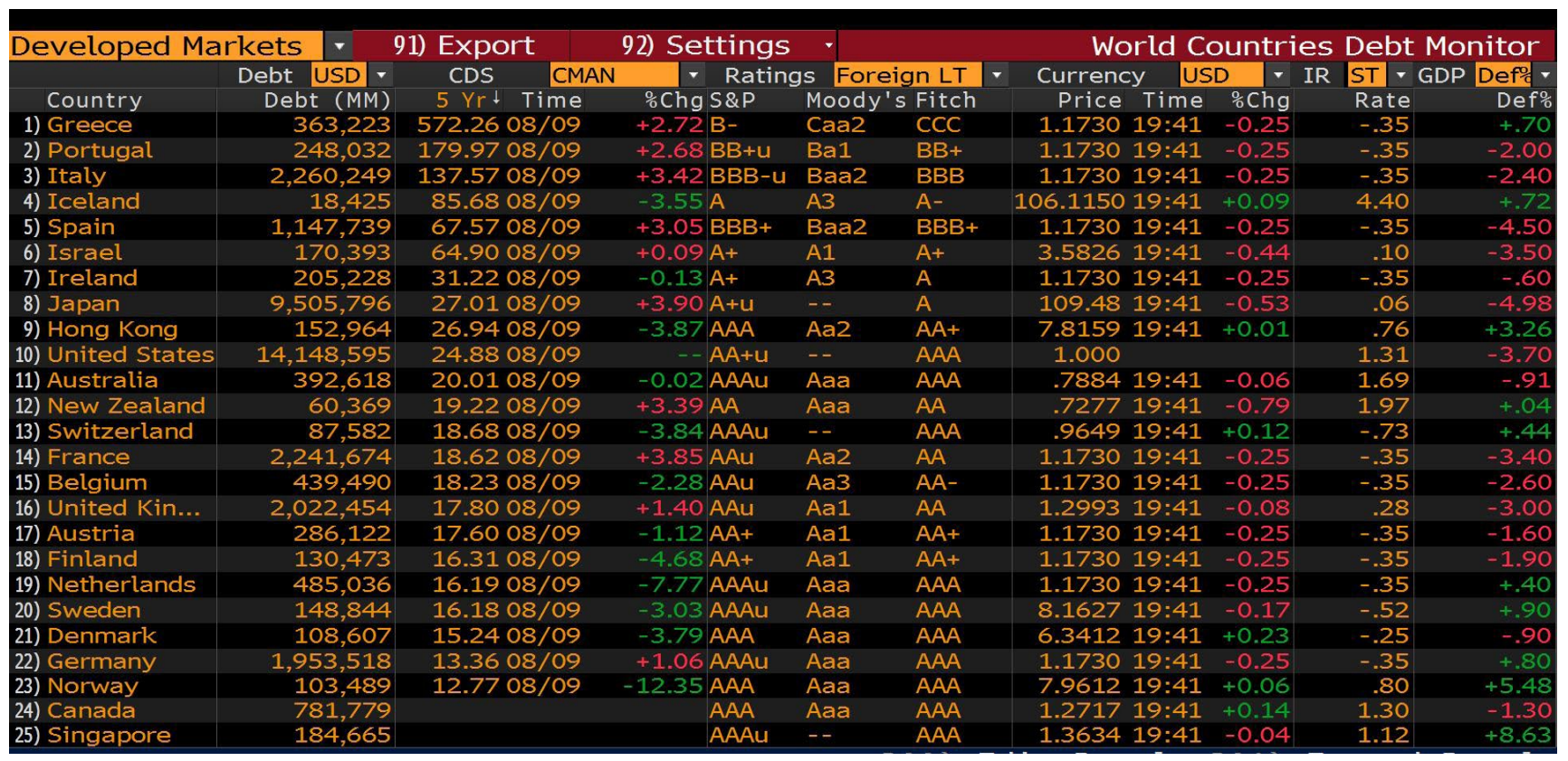

Figure 3. Source: Bloomberg.

To find the actual spreads, the country name followed by CDS was entered on Bloomberg. The 5 year CDS contract spread for Argentina is shown in (Figure 4).

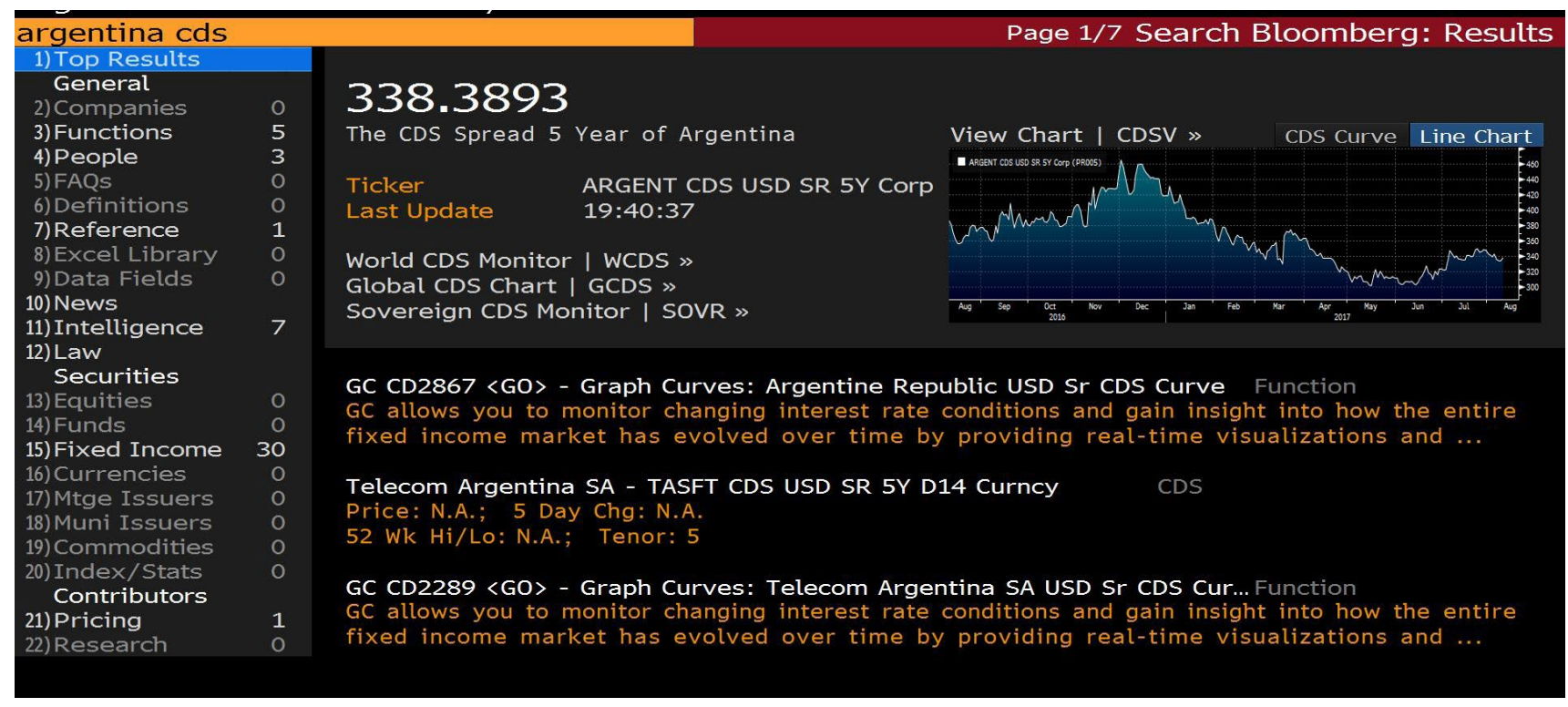

Figure 4. Source: Bloomberg. 
To study the historical spread, the GP function was used (Figure 5).

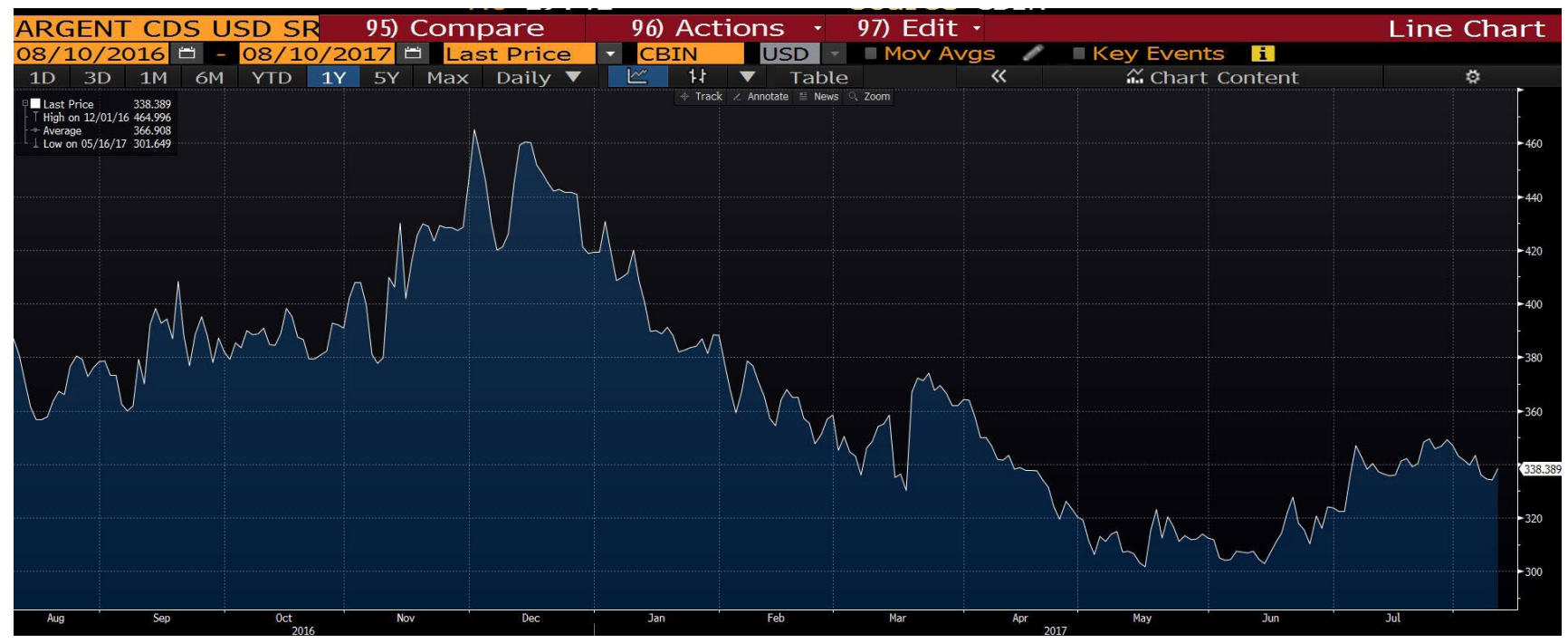

Figure 5. Source: Bloomberg.

The last input was the discounting rates for our model which will facilitate us to calculate the spread. We used the US Treasury bond yields to discount our model. The Treasury bond rate for one, three and five years is shown in Figure 6. To find the yields on various sovereign bonds, the WB function was used.

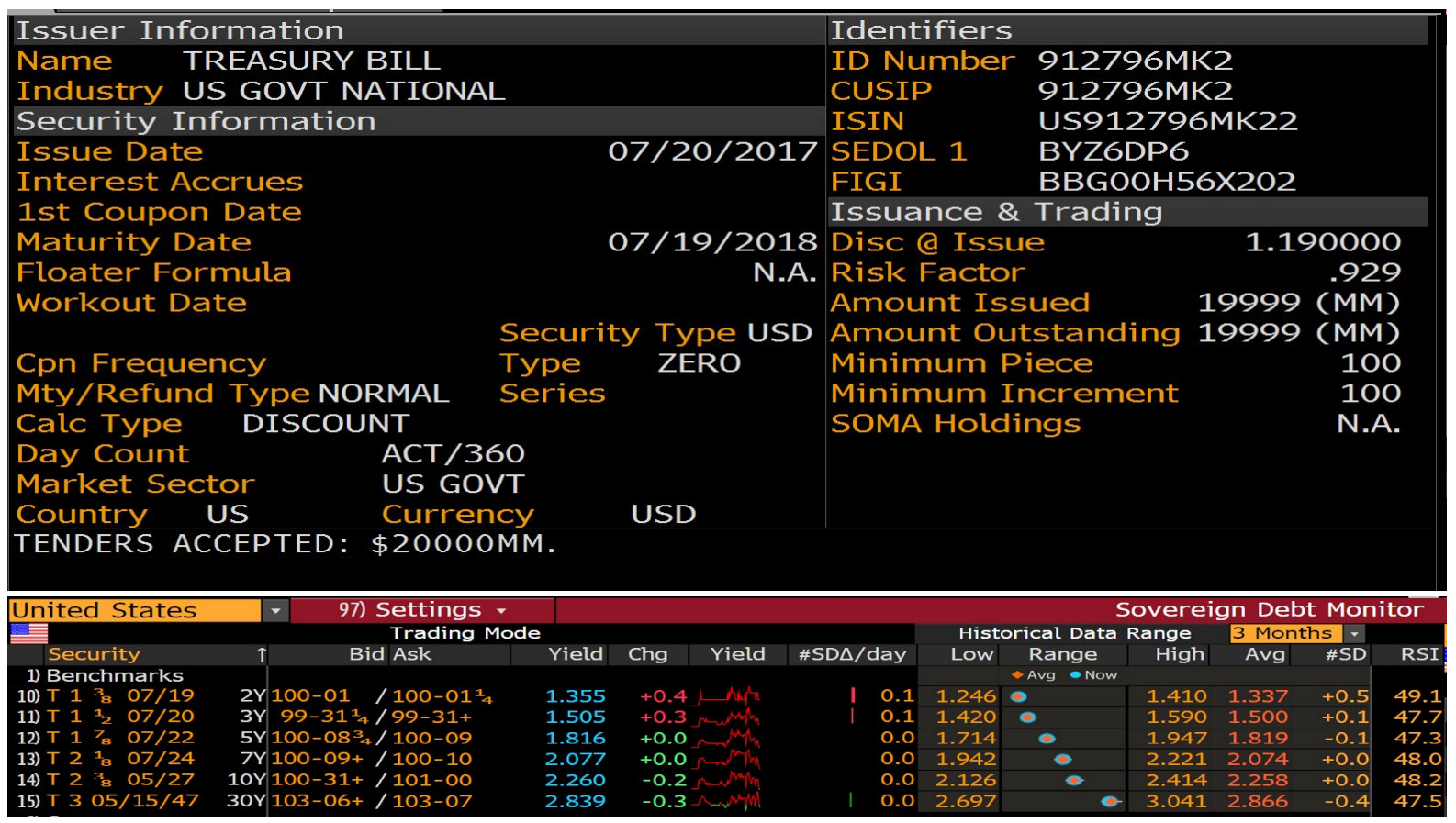

Figure 6. Source: Bloomberg. 


\section{Pricing Model}

To price a credit default swap for sovereigns, we made a few assumptions which the basis for the working of our model are. The assumptions of the model include:

- The frequency of credit event is made simpler in this model. The probability that a credit event will occur has been limited to a quarterly basis. This means that the credit event can happen only on the day of payment of premium by the protection buyer. Calculation of accrued interest has been negated.

- The US Treasury bond yield for similar maturing periods was taken as the discount rate.

- The market expectation was taken as the recovery rate. The recovery amount can be known only after a credit event happens and the International Swaps and Derivatives Association (ISDA) auction the underlying asset which determines the recovery rate.

- The notional principal for this model was assumed to be $\$ 1$.

The following inputs were used in this model:

- The probability of default of the underlying asset is a critical input. To arrive at this figure, historical data was analysed. S\&P comes out with the Sovereign historical default probabilities of bond based on the credit rating of the country. These bonds are the underlying assets of the CDS contract and thus any movement in the price of the bond will result in the movement of the CDS spread.

- The premium amount paid by the protection seller was calculated by multiplying the survival probability with the present value of the notional principal. The probability of default is calculated for each period and the total sum paid by the protection buyer was found.

- The contingent payment to be made by the seller after a credit event is calculated. This is obtained by multiplying the probability of default, the amount remaining after the recovery and the present value of the notional principal. We have taken a summation of these amounts over the period.

- The final calculation includes finding the spread which is the ratio of contingent amount paid by the seller to the premium paid by the buyer. This will determine the spread of the CDS contract.

\section{Step by Step Calculation of Spread}

Step 1: Determine the premium to be paid by the protection buyer. (Table 1)

\begin{tabular}{|r|r|r|r|r|}
\hline Year & Probability of Default & Survival probability & Discounting factor & Present Value of Payment \\
\hline 0.25 & 0.0050 & 0.9950 & 0.9970 & 0.9920 \\
\hline 0.5 & 0.0101 & 0.9899 & 0.9940 & 0.9840 \\
\hline 0.75 & 0.0150 & 0.9850 & 0.9911 & 0.9762 \\
\hline 1 & 0.0200 & 0.9800 & 0.9881 & 0.9683 \\
\hline & & & & 3.9205006 \\
\hline
\end{tabular}

Source: Author Calculation (Table 1)

Step 2: Determine the contingent Amount to be paid by the protection seller. (Table 2)

\begin{tabular}{|r|r|r|r|r|}
\hline Year & Probability of Default & Recovery rate & Discounting factor & Present Value of Payment \\
\hline 0.25 & 0.0050 & 0.2500 & 0.9970 & 0.0038 \\
\hline 0.5 & 0.0101 & 0.2500 & 0.9940 & 0.0075 \\
\hline 0.75 & 0.0150 & 0.2500 & 0.9911 & 0.0112 \\
\hline 1 & 0.0200 & 0.2500 & 0.9881 & 0.0148 \\
\hline & & & & $\mathbf{0 . 0 3 7 2 5 8 8}$ \\
\hline
\end{tabular}

Source: Author Calculation (Table 2) 
Step 3: Determine the Spread

To find the model spread, divide the results of table 2 with table 1.

For B- Rated countries, the spreads are as follows:

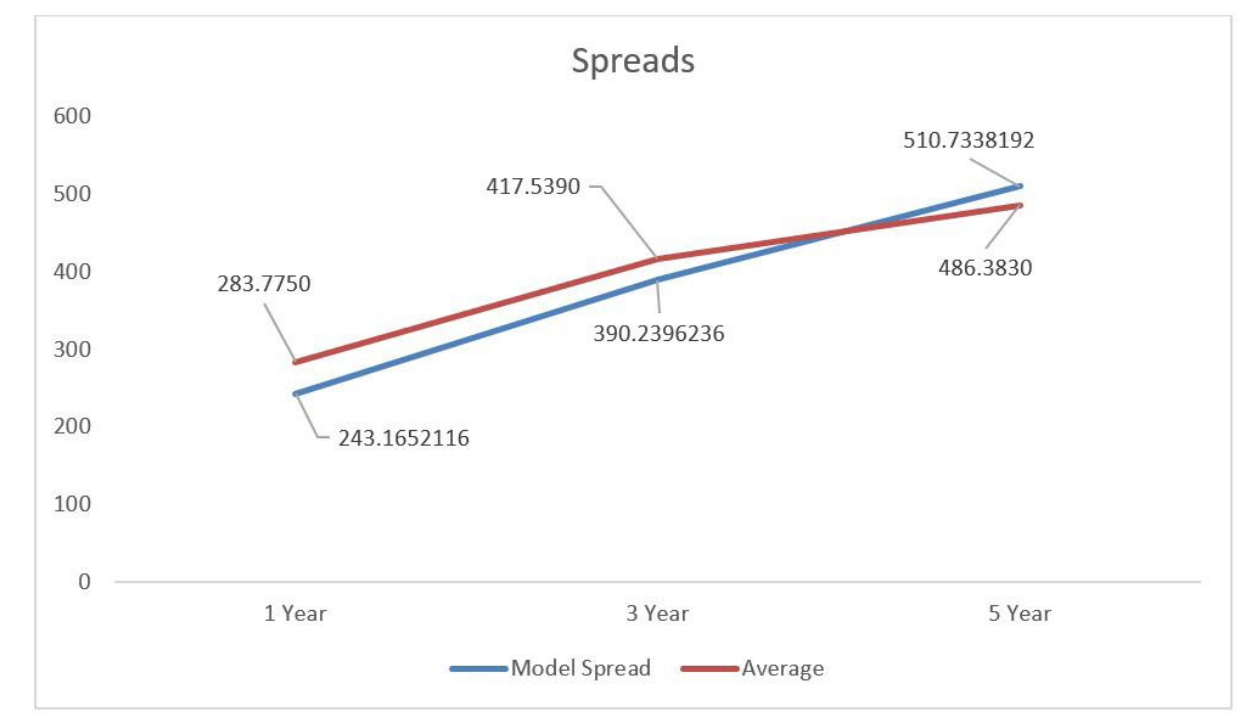

Source: Author Calculation (Graph 1)

\begin{tabular}{|l|l|l|l|l|l|l|l|}
\hline Year & Model Spread & Average & Iraq & Greece & Ukraine & Egypt & Lebanon \\
\hline Y Year & 243.1652 & 283.7750 & 279.0250 & 496.8450 & 230.8650 & 194.5550 & 217.5850 \\
\hline 3 Year & 390.2396 & 417.5390 & 456.3700 & 531.6200 & 446.9850 & 303.5600 & 349.1600 \\
\hline 5 Year & 510.7338 & 486.3830 & 520.5850 & 576.3550 & 540.0000 & 370.1300 & 424.8450 \\
\hline
\end{tabular}

Source: Author Calculation (Table 3)

For B Rated countries, the spreads are as follows:

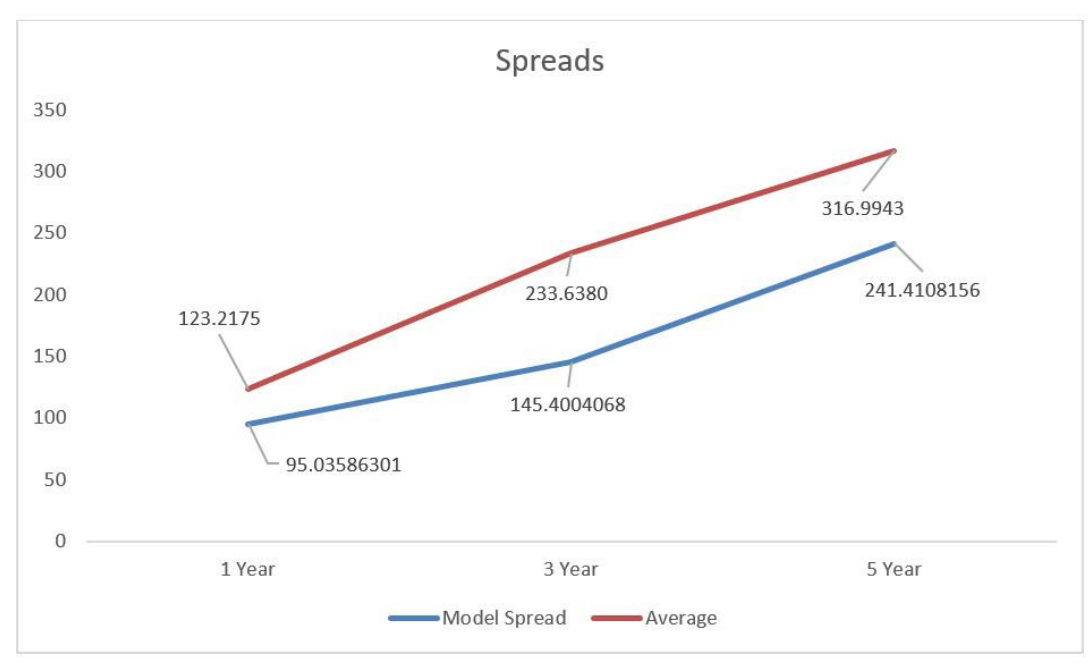

Source: Author Calculation (Graph 2) 


\begin{tabular}{|l|l|l|l|l|l|}
\hline Year & Model Spread & Average & Argentina & Nigeria & Pakistan \\
\hline 1 Year & 95.0358 & 123.2175 & 93.2476 & 186.315 & 90.09 \\
\hline 3 Year & 145.4004 & 233.6380 & 219.5739 & 276.23 & 205.11 \\
\hline 5 Year & 241.4108 & 316.9943 & 341.2629 & 344.765 & 264.955 \\
\hline
\end{tabular}

Source: Author Calculation (Table 4)

For BB- Rated countries, the spreads are as follows:

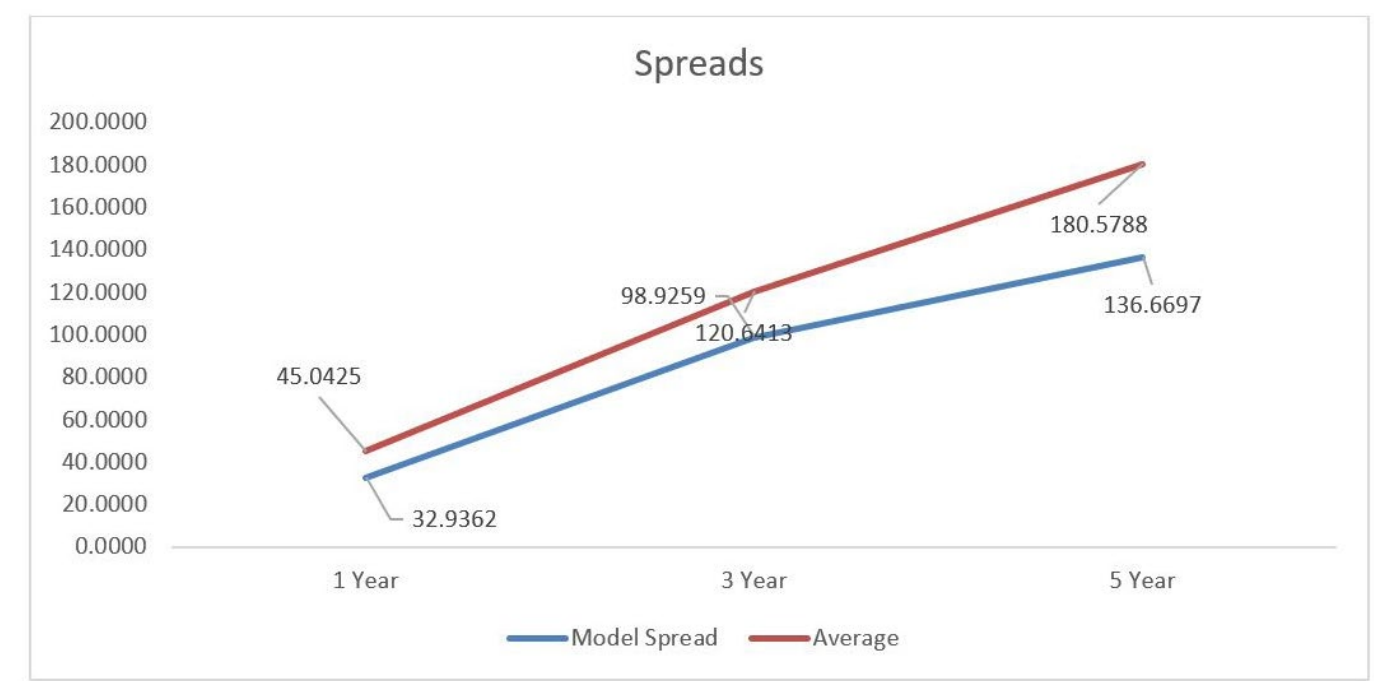

Source: Author Calculation (Graph 3)

\begin{tabular}{|l|l|l|l|l|l|l|}
\hline Year & Model Spread & Average & Bahrain & Costa Rica & Serbia & Vietnam \\
\hline 1 Year & 32.9362 & 45.0425 & 65.015 & 62.13 & 30.455 & 22.57 \\
\hline 3 Year & 98.9259 & 120.6413 & 170.09 & 144.055 & 89.435 & 78.985 \\
\hline 5 Year & 136.6697 & 180.5788 & 240.175 & 195.75 & 140.855 & 145.535 \\
\hline
\end{tabular}

Source: Author Calculation (Table 5)

\section{Limitations}

The differences in the spread are due to the limitations of our model. The key limitations of this model are as follows.

\section{- Credit event and Premium Payments are Restricted to a Quarterly Basis:}

Credit events cannot happen in between a quarter as per our model, but this was done for the simplicity of our model. Defaults can occur any day and thus accrual premiums are paid on the happening of a credit event in the real world.

\section{- Lack of Efficient Markets:}

The second limitation was that investors have full information and the spreads have taken all this information into consideration. Markets are imperfect and due to asymmetrical flow of information, the markets may not be a perfect representative of the true value of the spread.

\section{- Historical Data not a True Representative:}

We assumed that the default probability given by S\&P using historical information stands true but default probability for various credit ratings are dynamic. 
This dynamism is seen by looking at the 1 year actual spreads of two B- rated countries.

\begin{tabular}{|l|l|l|}
\hline Countries & Greece & Egypt \\
\hline 1 year Spread & 496.85Bps & 194.56Bps \\
\hline
\end{tabular}

Source: Author Calculation (Table 6)

\section{- Macro-economic Situations:}

The current macro-economic situations also affect the spreads. Drawing a reference from the above example, the spread of Greece is higher because of the current turmoil in their economy and Egypt is relatively doing well after they un-pegged themselves from the US dollar.

\section{Applications}

Apart from hedging and speculation, CDS pricing can be used for the following purposes:

- Arbitrage: The difference between the Sovereign CDS spread and the credit spreads of the underlying debt is called basis spread. Taking advantage of this difference is called basis trading. The strategy is based on the principle that a CDS is used to replicate cash flows of an underlying obligation. If the CDS spread is narrower than the credit spreads of the underlying instrument, arbitragers will profit by buying the underlying instrument and buying the CDS contract. In theory, the basis should always be zero as a result of this arbitrage activity but due to certain costs and market conditions, these transactions become profitable at times. (Security Exchange Commission, "A new look at the role of Sovereign Credit Default Swaps")

Loan Pricing: The study of CDS spreads can be used for pricing any loans given out to these sovereigns. Higher CDS spread would imply that the chances of default of these Sovereigns would be high and thus a higher credit premium should be charged on their loans. This is a powerful tool which generally used by various Commercial banks to price loans.

Predict the Future of an Economy: CDS spreads can predict the future movement of the economy. Futures market usually give a good prediction of the cash market, likewise an increase or decrease in spread can convey any changes in the economy.

For instance, CDS spreads were a great predictor of the Greece Sovereign debt crisis. The increase in CDS spread during that period enabled investors predict the downward trend in the market.

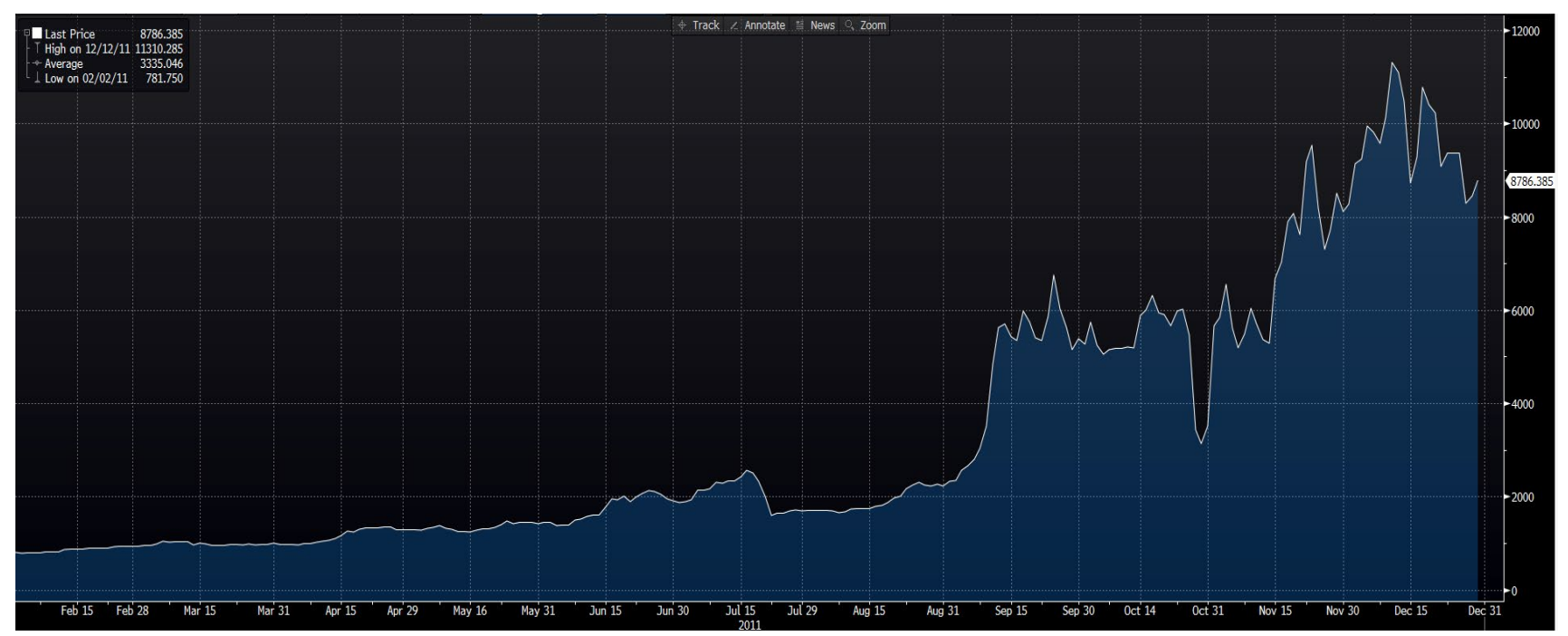

Source: Bloomberg (Figure 7). 


\section{Conclusion}

The valuation of a Credit default swap is a step-wise procedure. The present value (PV) of the payments made by the CDS buyer and the expected payoff by seller must be calculated.

Though this model is considered to be very powerful, very often, the calculated prices are not in tandem with the actual premiums. This is due to the various limitation which were seen earlier. Investor perception regarding the discounting factor becomes a crucial element which leads to variability in prices.

This model has been used by various financial institutions for pricing loans, understanding the state of economy and also used to derive the price of various over the counter (OTC) structured products.

\section{Bibliography}

Duffie, D. (1999). Credit Swap Valuation. Financial Analysts Journal.

Hull, J. C. Options Futures and Other Derivatives, Seventh Edition.

Hull, J. C., \& White, A. (2000, April). Valuiing Credit Default Swaps I: No Counterparty Default Risk. Toronto, Canada.

Jarrow, R. A., \& Turnbull, S. (1995). Pricing Options on Derivative Securities Subject to Credit Risk.

Moody's. (2017). Annual Sovereign Default Study and Rating Transitions.

Security Exchange Commission. A new look at the role of Sovereign Credit Default Swap.

Wen, Y., \& Kinsella, J. (2013). Credit Default Swap- Pricing Theory, Real Data Analysis and Classroom Application Using Bloomberg Terminal. New York. 